\title{
A systematic evaluation of the mother-to-child transmission potential of SARS-CoV-2 infection during pregnancy
}

Xuechen $\mathrm{Yu}^{1}$, Huijun $\mathrm{Chen}^{1}$, Fan $\mathrm{Luo}^{2}$, Juanjuan $\mathrm{Guo}^{1}$, Yuan Qiao ${ }^{1}$, Wei Zhang ${ }^{3}$, Jiafu $\mathrm{Li}^{1}$, Dongchi Zhao ${ }^{1}$, Dan $\mathrm{Xu}^{1}$, Qing Gong ${ }^{1}$, Lingyun Yang ${ }^{1}, \mathrm{Pu} \mathrm{Yang}^{1}$, Yuming Cao ${ }^{1}$, Xue Wen $^{4}$, Wei Hou ${ }^{2}$, Huixia Yang ${ }^{5}$, and Yuanzhen Zhang ${ }^{1}$

${ }^{1}$ Wuhan University Zhongnan Hospital

${ }^{2}$ Wuhan University

${ }^{3}$ Northwestern University Feinberg School of Medicine

${ }^{4}$ Affiliation not available

${ }^{5}$ Peking University 1st hospital

August 27, 2020

\begin{abstract}
Objective This study aimed to comprehensively evaluate the clinical characteristics of COVID-19 in perinatal period, and systematically assess the mother-to-child transmission potential of SARS-CoV-2. Design A case retrospective study. Setting and Population We retrospectively analyzed the data of 23 pregnant patients in late pregnancy. Methods Maternal and neonatal throat swabs, vaginal secretions, placenta tissues, and breast milk, were collected for the nucleic acid test of the virus. Pregnancy outcomes and neonatal results were also analyzed. Main Outcome Measures The result of viral nucleic acid test and pregnancy outcomes. Results Overall, 10 patients $(43.5 \%)$ had no symptoms and were found by routine chest CT. Complications appeared after COVID-19 onset included PROM (17.4\%) and fetal distress (4.3\%). Typical signs of viral pneumonia were recorded in chest CT of all patients. No patients developed severe pneumonia or died of COVID-19. All of 25 neonates were born alive. No severe asphyxia or neonatal death was observed. Although three neonates were tested transiently suspected positive for SARS-CoV-2 after being transferred to neonatology department, no newborns developed COVID-19. Only a rectal swab sample from one pregnant patient was tested positive for SARS-CoV-2, while all the other clinical specimens including first sample of newborn throat swabs were negative. Pathological examination found no obvious chorioamnionitis or clear virus inclusion body in placenta, and ACE2 (angiotension-converting enzyme 2) was expressed at a moderate level. Conclusions Asymptomatic patients were present in pregnant women. There is no confirmatory evidence for mother-to-child transmission in COVID-19 patients with late pregnancy.
\end{abstract}

\section{Hosted file}

Manuscript-0826.doc available at https://authorea.com/users/354397/articles/477984-asystematic-evaluation-of-the-mother-to-child-transmission-potential-of-sars-cov-2infection-during-pregnancy

\section{Hosted file}

Table 1.docx available at https://authorea.com/users/354397/articles/477984-a-systematicevaluation-of-the-mother-to-child-transmission-potential-of-sars-cov-2-infection-duringpregnancy

\section{Hosted file}


Table 2.docx available at https://authorea.com/users/354397/articles/477984-a-systematicevaluation-of-the-mother-to-child-transmission-potential-of-sars-cov-2-infection-duringpregnancy
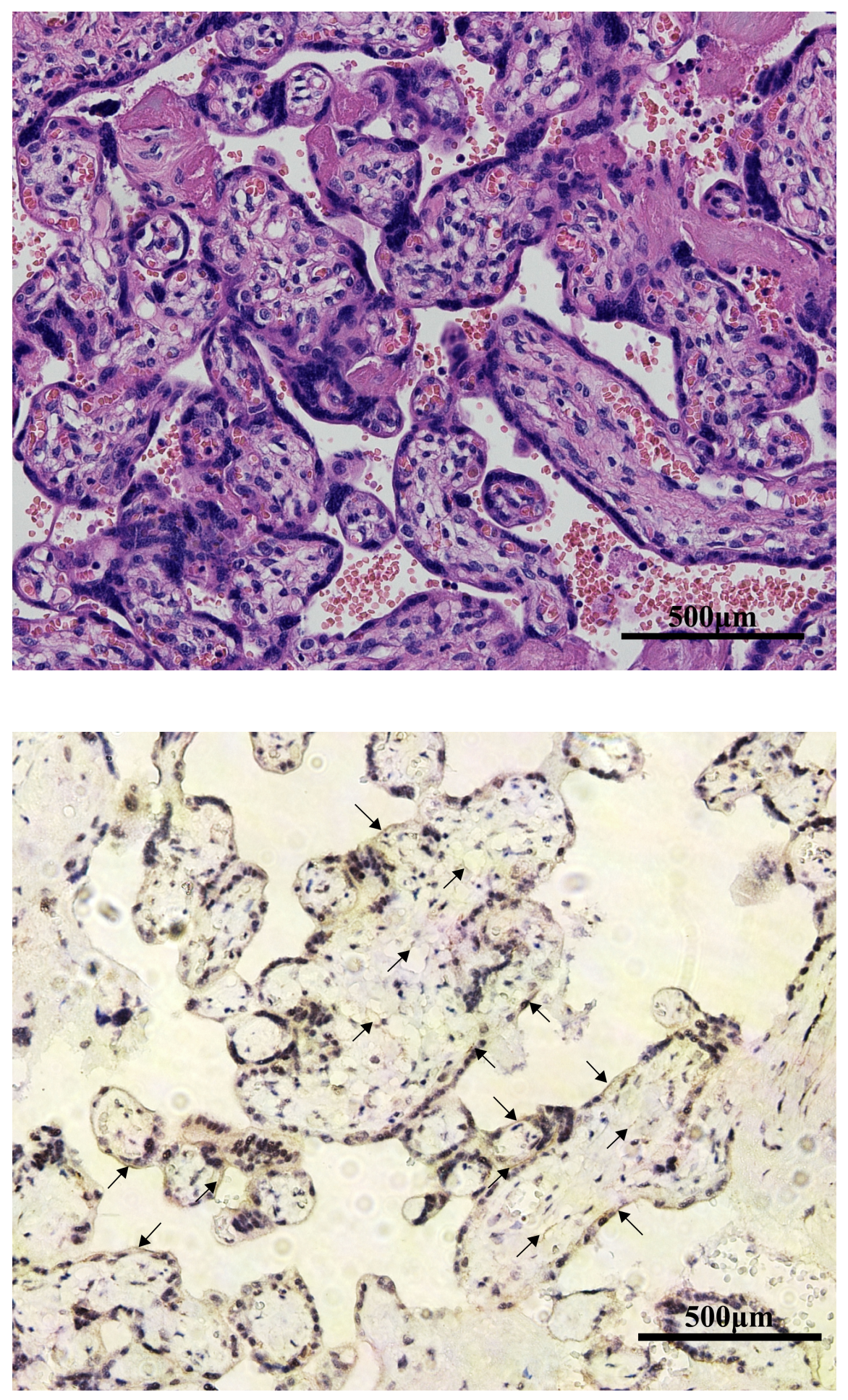